\title{
The Chemopreventive Potential of Diosmin and Hesperidin for COVID-19 and Its Comorbid Diseases
}

\author{
Rohmad Yudi Utomo ${ }^{1,2}$, Muthi' Ikawati ${ }^{1,3}$, Dyaningtyas Dewi Pamungkas Putri ${ }^{1,4}$, Irfani Aura \\ Salsabila ${ }^{1}$, Edy Meiyanto ${ }^{1,3^{*}}$ \\ ${ }^{1}$ Cancer Chemoprevention Research Center, Faculty of Pharmacy, Universitas Gadjah Mada (UGM), Sekip Utara, \\ Yogyakarta 55281, Indonesia \\ ${ }^{2}$ Medicinal Chemistry Laboratory, Department of Pharmaceutical Chemistry, Faculty of Pharmacy, UGM, Sekip Utara, \\ Yogyakarta 55281, Indonesia \\ ${ }^{3}$ Macromolecular Engineering Laboratory, Department of Pharmaceutical Chemistry, Faculty of Pharmacy UGM, Sekip \\ Utara, Yogyakarta 55281, Indonesia \\ ${ }^{4}$ Department of Pharmacology and Clinical Pharmacy, Faculty of Pharmacy UGM, Sekip Utara, Yogyakarta 55281, \\ Indonesia
}

\begin{abstract}
The COVID-19 becomes worse with the existence of comorbid diseases such as cardiovascular diseases, metabolic syndromes, inflammation, degenerative diseases, as well as cancer. Therefore, a comprehension approach is needed to combat such comorbid conditions, not only focusing on the virus infection and replication but also directed to prevent the raising comorbid symptoms. This study analyzed the potential natural compounds, especially diosmin and hesperidin, as an anti-SARS-CoV- 2 and chemopreventive agent against several COVID-19 comorbid diseases by using an in-silico method. Diosmin and hesperidin together with other natural compounds and existing viral drugs (lopinavir, nafamostat, and comastat) were docked into several proteins involved in SARS-CoV-2 infection and replication namely SARS-CoV-2 protease (PDB:6LU7), spike glycoproteinRBD (PDB:6LXT), TMPRSS2, and PD-ACE2 (PDB:6VW1) using MOE software. The interaction properties were determined under docking score values. The result exhibited that diosmin and hesperidin performed superior interaction with all the four proteins compared to the other compounds, including the existing drugs. Moreover, under literature study, diosmin and hesperidin also elicit good chemopreventive properties against cardiovascular disorder, lung and kidney degeneration, as well as cancer development. In conclusion, diosmin and hesperidin possess high opportunity to be used for the COVID-19 and its the comorbid diseases as chemopreventive agents.
\end{abstract}

Keywords: chemoprevention, COVID-19, diosmin, hesperidin, SARS-CoV-2 infection

\section{INTRODUCTION}

The COVID-19 epidemic has spread evenly throughout the world and it is still difficult to predict how it will end. The virus that causes COVID-19 is quite strange because in addition to being fatal to certain people, especially to the comorbid patients with cardiovascular, diabetes

Submitted: October 27, 2020

Revised: November 11, 2020

Accepted: November 11, 2020

*Corresponding author: edy_meiyanto@ugm.ac.id 
mellitus, and renal dysfunction, it can also spread to regions with various climates at the same time (Guan, et. al., 2020; Iqbal, et. al., 2020). Until now, various types of drugs have been tested but nothing has been stated as an effective drug to overcome this disease (Cao, et. al., 2020). It is estimated that this pandemic problem will last a long time.

So far, the therapeutic approach to dealing with COVID-19 patients is to relieve symptoms and treat the comorbidities. COVID-19 patients who have comorbidities suffer with worse symptoms (Rosser and Ritchie, 2020). Treatment with direct targets to the virus is currently in trials and is not yet a recommended drug. The development of vaccines that are continuously being carried out by various parties also still requires a relatively long time to be used (Folegatti, et. al. 2020; Zhu, et. al., 2020). Meanwhile, research on the molecular characteristics of viruses is increasingly able to reveal more details about the shape, components, and structure of the macromolecules that make up viruses that practically encourages the development of targeted drugs or vaccines. However, the development of new drugs is not the right choice because it will require a lot of time and resources and is considered less effective (Chan, et. al., 2020; Wrapp, et. al., 2020). The approach through drug repurposing offers little hope, but still does not show the best results. However, the basic problem from repurposing the existing drugs is the raising of adverse effects in a long-term usage (Harrison, 2020 ; Plaze, et. al., 2020). Therefore, efforts to overcome these problems need to think about ways to provide alternative medicine in the long-term usage (Parvathaneni and Gupta, 2020).

Natural ingredients are commonly used among Asian people to enhance their immunity in daily life. Citrus fruits, one of the natural ingredients, not only contain vitamin $\mathrm{C}$ which is beneficial to the body but also contain lots of methoxy flavonoids, especially in the peel of the fruit, such as hesperitin, hesperidin, and diosmin, an enantiomer structure of hesperidin (Ikawati, et. al., 2019;
Meneguzzo, et. al., 2020). Hesperetin is an aglycone form of hesperidin and its molecular docking shows to bind to the ACE-2 receptor, a protein that is believed to be an intermediary for the entry of the SARS-COV-2 virus into the host cell. The ability to bind to ACE-2 of compounds is believed that these compounds will be able to inhibit viral infections (Meneguzzo, et.al., 2020; Utomo, et.al., 2020). In addition to citrus, there are still some herbs that are often used to maintain body warmth and fitness, such as turmeric, galangal, and ginger (Da'i, et. al., 2019; Darmawan and Pramono, 2016). Some compounds that are known to have pharmacological significance are curcuminoids, galangin, ACA, and several types of flavonoids in oranges. On the other hand, ACE-2 later found not to be the only major variable in the process of viral infection, but there were still several important proteins that contribute to the effect such as TMPRSS2 (Thunders and Delahunt, 2020). Therefore, the study of the ability of these compounds to interact with the essential-mediated viral infection proteins needs to be explored, especially for the compounds that possess the ability to prevent the comorbid diseases of COVID-19.

This study was conducted to measure the potential of natural compounds from oranges (Citrus sp.), turmeric, and galangal as anti COVID-19 through molecular docking studies. Molecular docking is carried out on 4 types of target proteins that are considered essential in the SAR-CoV-2 infection process. These proteins are (1) ACE-2 which is a protein/receptor recognized by the SARS-CoV-2 spike protein (Wrapp, et. al., 2020), (2) TMPRSS2, which is a protein that has protease activity that cuts S2 viral glycoprotein allowing endocytosis of virus (Lukasen, et. al., 2020), (3) 3CL-pro which is a viral protease that cuts post-translational protein to prepare viral structural proteins (Tahir, et. al., 2020), and (4) spike glycoprotein $\mathrm{RBD}$, a protein used to bind to ACE-2 (Chan, et. al., 2020; Wrapp, et. al., 2020). By looking at the binding pattern, it can predict the 
most potential compounds to be developed as the best antidote for viruses. In addition, we also discuss this issue in correlation with the potential of natural occurring compounds, namely diosmin and hesperidin, to prevent cancer development and the comorbidities diseases of COVID-19.

\section{METHODS}

\section{Protein and Ligand Preparation}

Crystal structure for molecular docking used the available model in the PDB database. The model of RBD-S used PDB ID 6VSB due to the information of prefusion spike glycoprotein structure containing single receptor-binding domain while PDB ID 6LXT was used as the model of S2 subunit of spike glycoprotein in complex with $\mathrm{H} 2$ domain. The PDB ID 6VW1 was used as the model of PDACE2 in complex with RBD of SARS-CoV-2. For the crystal structure of SARS-CoV-2 protease, $\mathrm{PDB}$ ID 6LU7 was used which informed the structure of $3 \mathrm{CL}$ protease in complex with protease inhibitor. All the protein structure was prepared by removing the water molecule then generated for protonate $3 \mathrm{D}$ model and partial charge calculation. On the other hand, the chemical structure of all chemical compounds was obtained from the Pubchem, then was drawn in ChemDraw Professional 16 (PerkinElmer, USA) followed by conformational search and energy minimization in MOE 2010.10 (Chemical Computing Group, Canada).

\section{Homology Modelling}

Due to the non-availability crystal structure, we performed a homology modelling approach from available amino acid sequence retrieved from Uniprot (https://www.uniprot.org/uniprot/O15393) to prepare the structure of TMPRSS2 protein. We performed homology modelling in MOE 2010.10 software following the default step preparation. The closest sequence alignment was chosen sharing more than $95 \%$ similarity to generate the predicted-crystal structure. Crystal structure model was evaluated at the Z-score value and Ramachandran plot. The obtained TMPRSS2 model was prepared following the protein preparation procedure.

\section{Molecular Docking Simulation}

Molecular docking study was chosen to be the tools for screening the binding affinity of several natural products on SARS-CoV-2 marker protein, RBD-S, PD-ACE2, and SARS-Cov-2 protease. All computational simulation was conducted on Windows 10 Operating System, Intel Core i7-10th Gen as a processor with 8 GB of RAM. Molecular docking study including docking simulation, RMSD calculation, and visualization of binding interaction was performed using MOE 2010.10 software. The default settings were used with no further explanation. The docking simulation setting used London $\mathrm{dG}$ and Triangle matcher as score function and placement setting method. Forcefield method was used to refine the docking results from 30 retain settings. Results of the molecular docking described the affinity represented by docking score and binding interaction of each compound on the protein targets.

\section{RESULT AND DISCUSSION}

Previously we reported the anti SARSCoV-2 activity of natural occurring compounds of 4 medicinal herbs species that are commonly used in relieving diseases, namely Curcuma sp., Citrus sp., Caesalpinia sappan, and Alpinia galanga (Utomo, et. al., 2020). We further selected some specific compounds from the chemical constituent of each herbs (Figure 1.) to be evaluated together with the existing antiviral drugs, lopinavir, nafamostat, and camostat.

We used several representative compounds of each plant which are known to have pharmacological benefits (Figure 1). We classified the prospected compounds into 4 groups, the existing drugs (lopinavir, nafamostat, camostat), compounds contained in Curcuma sp., Citrus sp., Caesalpinia sap- 
pan, and Alpinia galanga. Lopinavir is an existing antiviral drug which is now being repurposed for SARS-CoV-2 infection treatment, conducted in China (Chen and Du, 2020; Cao, et. al., 2020). Same case different states happened with $\mathrm{Na}-$ famostat and Camostat, existing serine protease inhibitors for treating pancreatitis, also proposed for its antiviral activity due to its correlation in TMPRSS2 inhibition (Thunders and Delahunt, 2020).

The three existing drugs are now undergoing clinical trials expected to be the promising cure for SARS-CoV-2 infection. We object to un- veil the possible potential from Citrus sp., Curcuma sp., Caesalpinia sappan, and Alpinia galanga to prevent the COVID-19 or other diseases. Hesperidin and diosmin content are apparently approved as registered anti-hemorrhoid drugs. With a good pharmacokinetic profile and relatively nontoxic, hesperidin and diosmin are also possible for being re-purposed for any potential indication as they already possessed a promising in vitro, in vivo, and clinical trials history. Curcuminoids major compound found in Curcuma sp. showed its clinical potential also worth promoting as an alternative candi-

A
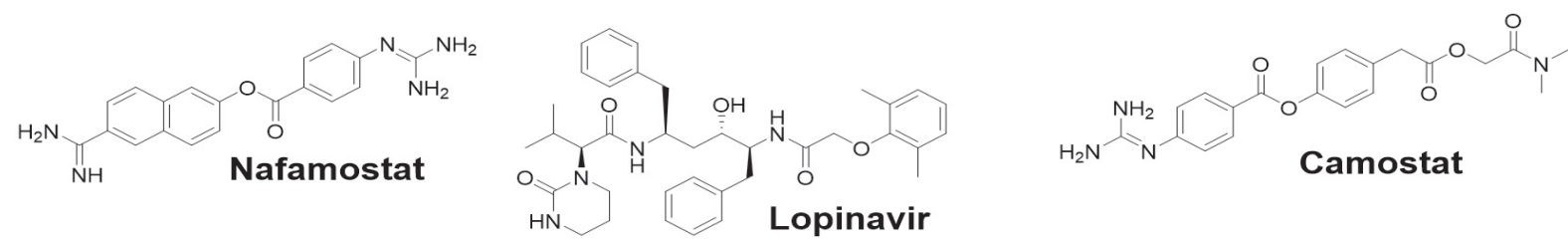

B
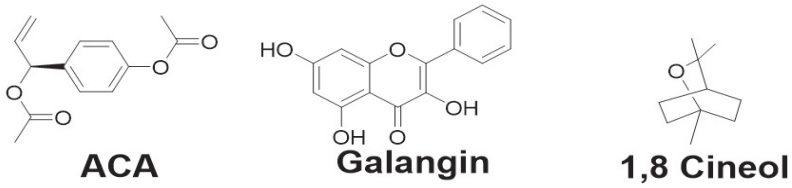

C

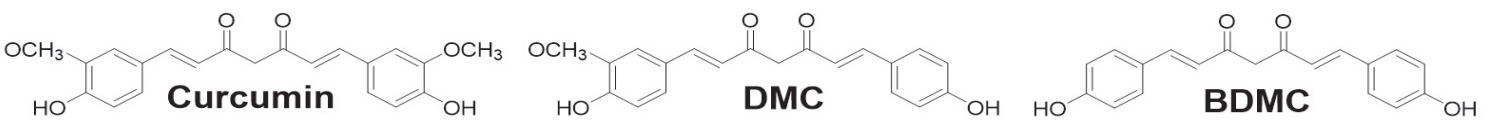

D

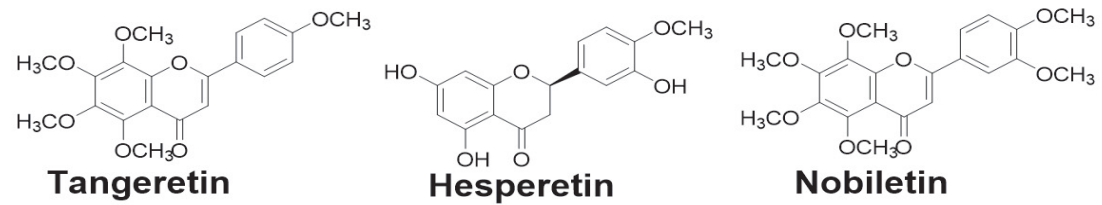<smiles>COc1ccc(C2CC(=O)c3c(cc(OC4OC(OCC5CC(C)C(O)C(O)C5O)C(O)C(O)C4O)c(O)c3O)O2)cc1O</smiles>

Hesperidin<smiles>O=C1CC(c2ccc(O)cc2)Oc2cc(O)cc(O)c21</smiles>

Naringenin<smiles></smiles>

E

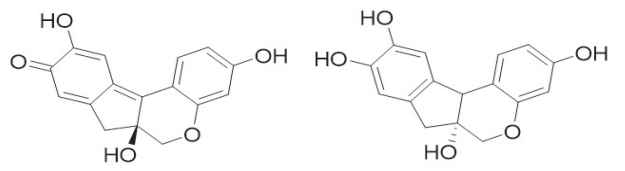

Brazilein

Brazilin

Figure 1. Chemical compounds used for the molecular docking screening. Current drug for SARS-CoV-2 therapy (A). Natural compound contained in Alpinia galanga (B). Natural compound contained in Curcuma sp.(C). Natural compound contained in Citrus sp. (D). Natural compound contained in Caesalpinia sappan (E). ACA: Aceto Cavicol Acetate; DMC: Desmethoxylcurcumin; BDMC: Bisdesmethoxylcurcumin. 

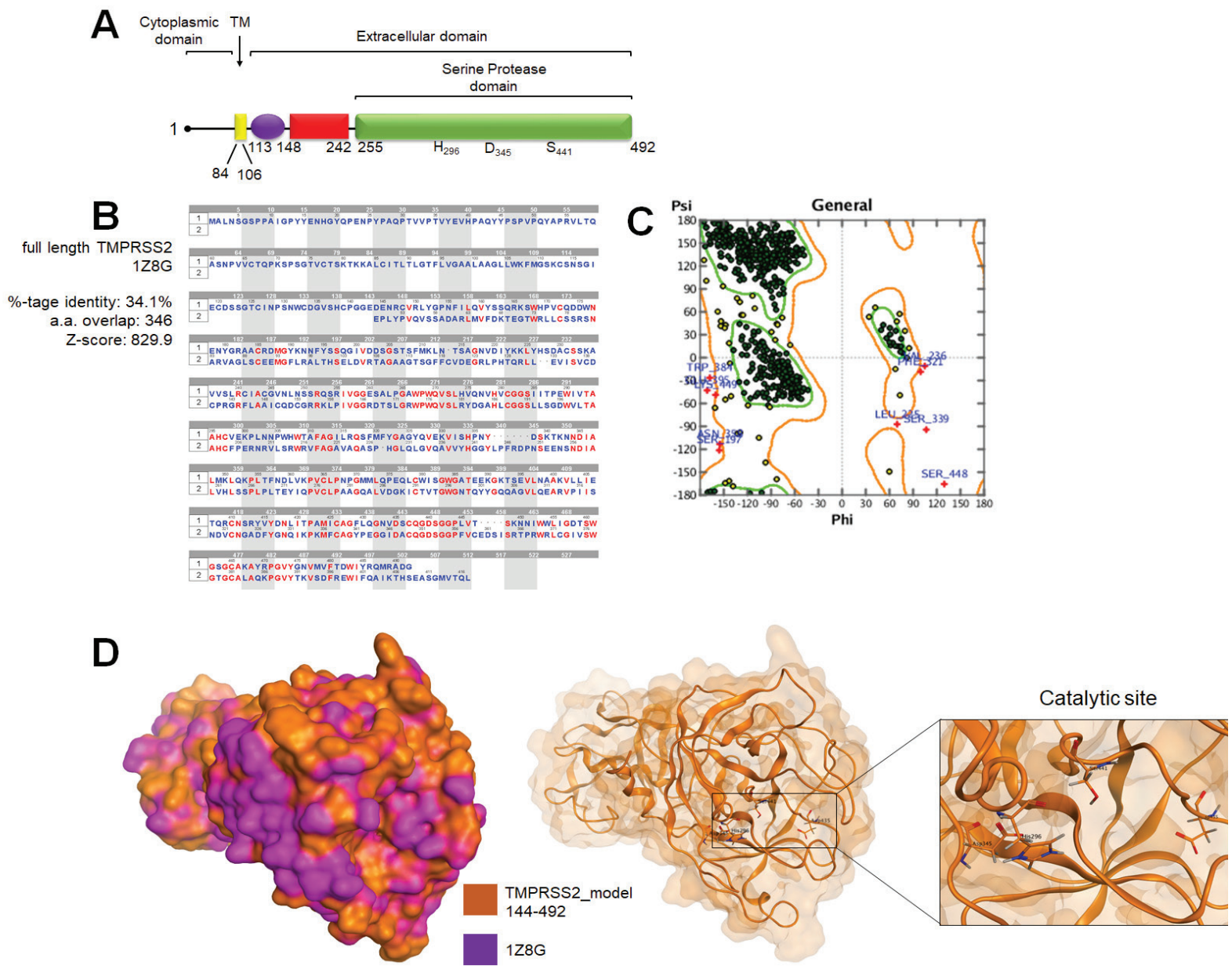

Figure 2. Crystal structure model of TMPRSS2. (A). Structural domain of full length-TMPRSS2 (B). Sequence alignment between TMPRSS with serine protease hepsin (PDB ID: 1Z8G) (C). Ramachandran plot of TMPRSS2 from homology modelling (D). Structure of TMPRSS2 retrieved from homology modelling using 1 Z8G as the template and its catalytic site.

date for combating SARS-CoV-2 infection (Utomo, et. al.,2020). For additional, brazilin and brazillein from Caesalpinia sappan as well as Acetoxychavicol Acetate (ACA) and galangin from Alpinia galanga also showed antiviral activities in comparison with the rest selected compounds (Da'i, et. al., 2019; Meiyanto and Larasati, 2019).

We cautiously selected certain targets to predict the anti-SARS-CoV-2 activity from each compound. We used molecular docking with 4 target receptors including SARS-CoV-2 protease (PDB:6LU7), Spike glycoprotein-RBD (PDB:6LXT), TMPRSS2, and PD-ACE2
(PDB:6VW1). These receptors are believed to contribute in virus infection in comparison with the respected known ligand or drugs as references. All of the target proteins are available as crystal structure in PDB except TMPRSS2. TMPRSS2 is a transmembrane receptor that exists in various tissues. This receptor contains a serine protease domain that is involved in viral infection.

Structural domain of TMPRSS2 consist of cytoplasmic domain and extracellular, which TMPRSS2 consist of 492 amino acids (Figure 2.A). The protease domain is denoted as part of extracellular domain followed by hydrophobic trans- 
Indonesian Journal of Cancer Chemoprevention, October 2020

Table 1. Docking Score of Natural Compounds towards several potential binding domain of COVID-19.

\begin{tabular}{|c|c|c|c|c|c|c|}
\hline \multirow[b]{2}{*}{ Plant source } & \multirow[b]{2}{*}{ Ligand } & \multicolumn{4}{|c|}{ Delta Energy Gibbs $(\Delta \mathrm{G})(\mathrm{Kcal} / \mathrm{mol})$} & \multirow[b]{2}{*}{ TMPRSS2 } \\
\hline & & $\begin{array}{c}\text { Protease } \\
\text { Domain } \\
(6 L U 7)\end{array}$ & $\begin{array}{c}\text { Spike } \\
\text { glycoprotein- } \\
\text { RBD (6VSB) }\end{array}$ & $\begin{array}{l}\text { S2 Subunit } \\
(6 \mathrm{LXT})\end{array}$ & $\begin{array}{l}\text { PD-ACE2 } \\
\text { complex -S } \\
(6 \mathrm{VWI})\end{array}$ & \\
\hline- & Lopinavir & -11.62 & - & - & - & - \\
\hline- & Nafamostat & - & -7.17 & - & - & -11.30 \\
\hline \multirow[t]{2}{*}{ - } & Camostat & - & -7.49 & - & - & -11.19 \\
\hline & Curcumin & -11.82 & -8.39 & -8.15 & -9.04 & -9.91 \\
\hline \multirow[t]{4}{*}{ Curcuma longa } & DMC & -11.21 & -6.41 & -6.86 & -8.04 & -11.97 \\
\hline & BDMC & $-|1.5|$ & -8.64 & -8.44 & -7.48 & -10.70 \\
\hline & Tangeretin & -10.55 & -8.18 & -8.81 & -6.51 & -11.92 \\
\hline & Hesperetin & -12.36 & -9.08 & -8.97 & -6.71 & -12.08 \\
\hline \multirow{4}{*}{ Citrus sp. } & Hesperidin & $-13.5 \mid$ & -9.61 & -9.37 & -10.67 & -12.71 \\
\hline & Nobiletin & -10.38 & -7.76 & -7.07 & -7.88 & -10.03 \\
\hline & Naringenin & -12.44 & -7.40 & -8.65 & -7.69 & -10.19 \\
\hline & Diosmin & -14.77 & -9.48 & -9.01 & -10.98 & -14.16 \\
\hline \multirow{3}{*}{$\begin{array}{l}\text { Caesalpinia } \\
\text { sappan }\end{array}$} & Brazilein & -10.52 & -7.56 & -8.46 & -7.43 & -8.67 \\
\hline & Brazilin & -12.36 & -7.50 & -8.52 & -7.49 & -7.41 \\
\hline & Galangin & -12.96 & -7.89 & -8.88 & -7.60 & -7.97 \\
\hline \multirow[t]{2}{*}{ Alpinia galanga } & & & & & & \\
\hline & $\mathrm{ACA}$ & -9.94 & -6.05 & -6.89 & -6.16 & -6.28 \\
\hline
\end{tabular}

membrane domain, a stem region and a protease domain containing a catalytic amino acid that plays an important role for proteolytic activity comprising histidine, aspartic acid and serine. The autocleavage of $32 \mathrm{kDa}$ serine protease will be secreted extracellular to interact with any proteins neighboring cells including the extracellular matrix and cell surface proteins (Thunders and Delahunt, 2020; Afar, et. al., 2001). The SARS-CoV-2 spike glycoprotein is the substrate of TMPRSS2 which later initiates the entry of SARS-CoV-2 into the cell's host. However, the complete TMPRSS2 structure specific SARS-CoV-2 to enter the cells is unknown yet. Beforehand we validate the crys- tal structure of TMPRSS2. As the crystal structure of TMPRSS2 is not available yet in PDB, we used 1Z8G that has homology in humans with 417 amino acids (Hussain, et. al., 2020; Sakai, et. al., 2014). Our homology modelling showed the favorable Z-score and over 90 percent of residue fall in the core region of Ramachandran plot indicating the valid model (Figure 2B \& C). In addition, we also found the catalytic site of TMPRSS2 consisting of His296, Asp345, Asp435, and Ser441 as the important binding site for molecular docking study.

Docking simulation of all the compounds exhibited good interaction with the protein targets with various score values (Table 1). Diosmin and 
A
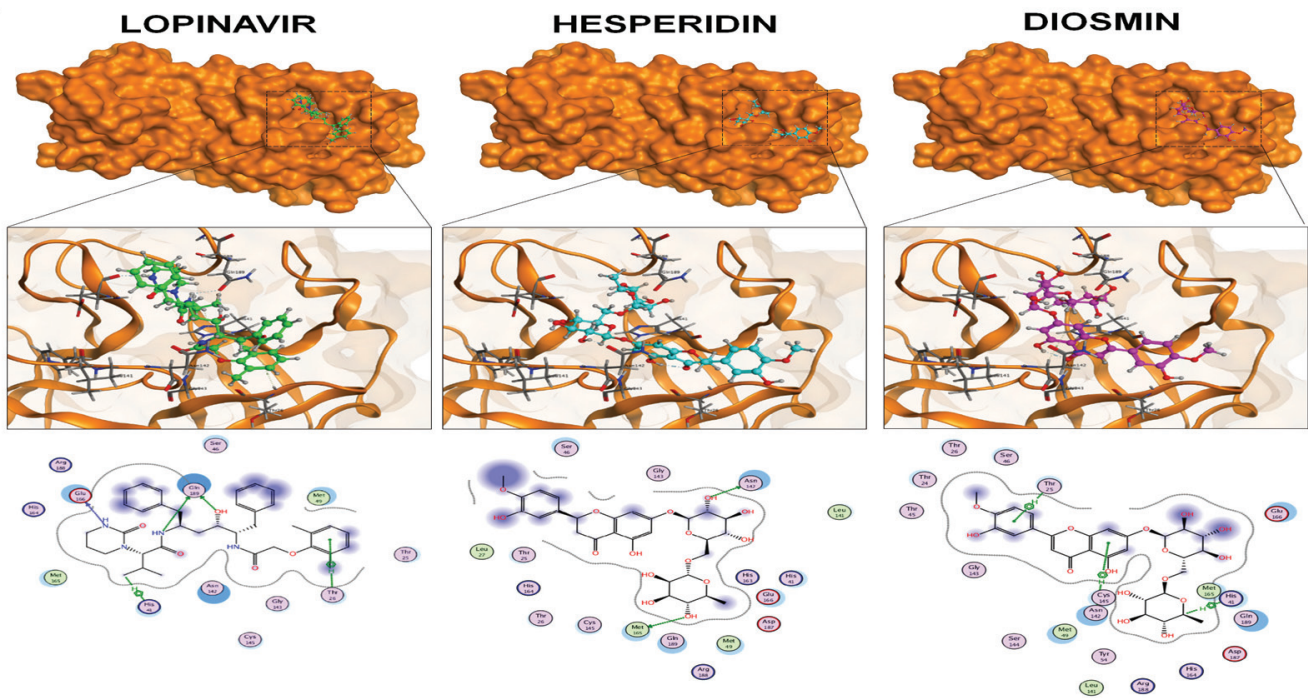

B
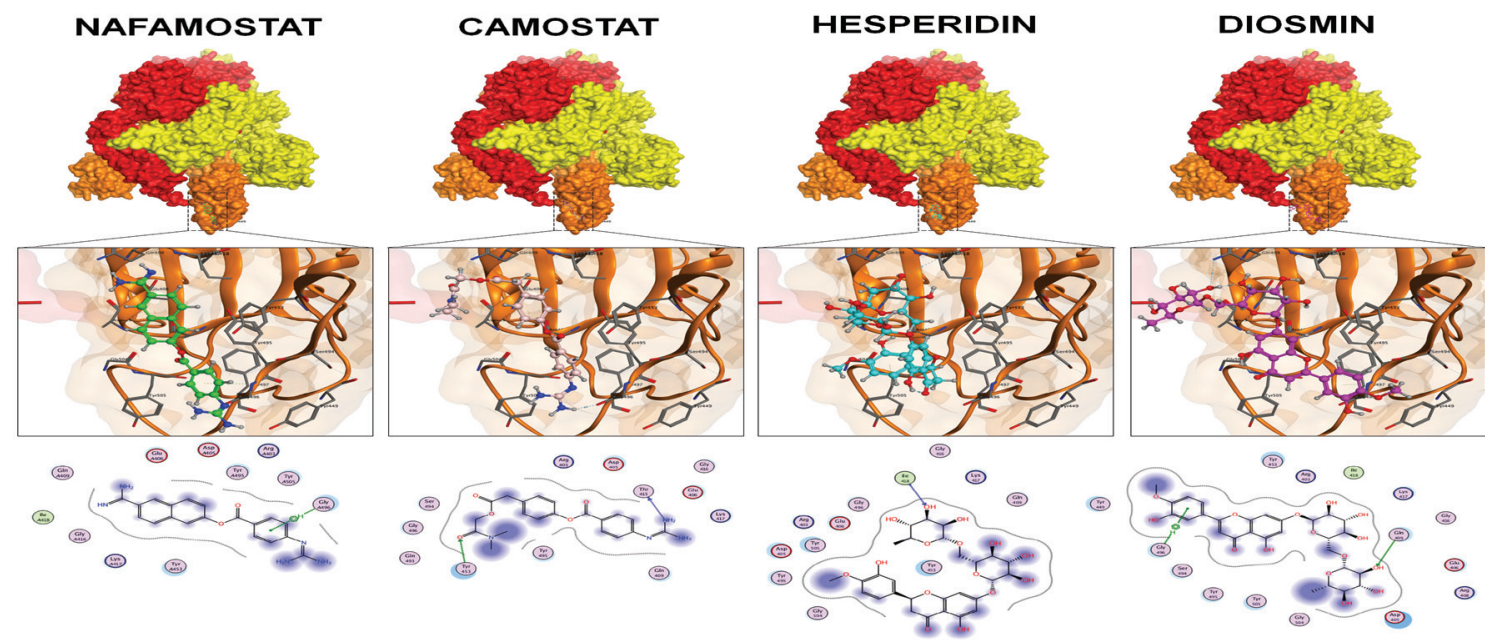

Figure 3. (A). Binding interaction of lopinavir, hesperidin, and diosmin on protease domain of SARS-Cov-2. Protease domain structure was shown in orange-color surface and ribbon while the compound was in a ball and stick-colored atom. (B). Binding interaction of nafamostat, camostat, hesperidin, and diosmin on RBD of spike glycoprotein. Trimeric spike glycoprotein was shown on the colored surface while the RBD site was highlighted in a dashed line. All of the compound was represented in a ball and stick-colored atom.

hesperidin show stronger interaction on RBD-S (6VSB) compared to other marker compounds of Curcuma sp., Sappan wood, galangal, and Citrus $s p$. Since diosmin and hesperidin perform better interaction on RBD-S, the single receptor binding domain of Spike Glycoprotein that used to bind on Protease Binding Domain of ACE2 (PD-ACE2), then we elucidated the molecular sharing interaction between the compounds and the target domain. We compared both interactions with nafamostat and camostat which are known to possess binding interaction with the target domain. Diosmin and hesperidin showed relatively low binding energy of interaction with $\Delta \mathrm{G}$ of -9.48 and $-9.61 \mathrm{Kcal} / \mathrm{mol}$ respectively compared to nafamostat and camostat with $\Delta \mathrm{G}$ of -7.17 and $-7.49 \mathrm{Kcal} / \mathrm{mol}$ respectively. All the compounds could interact with the target domain in the same amino acid residues, namely Gly496, but hes- 
A

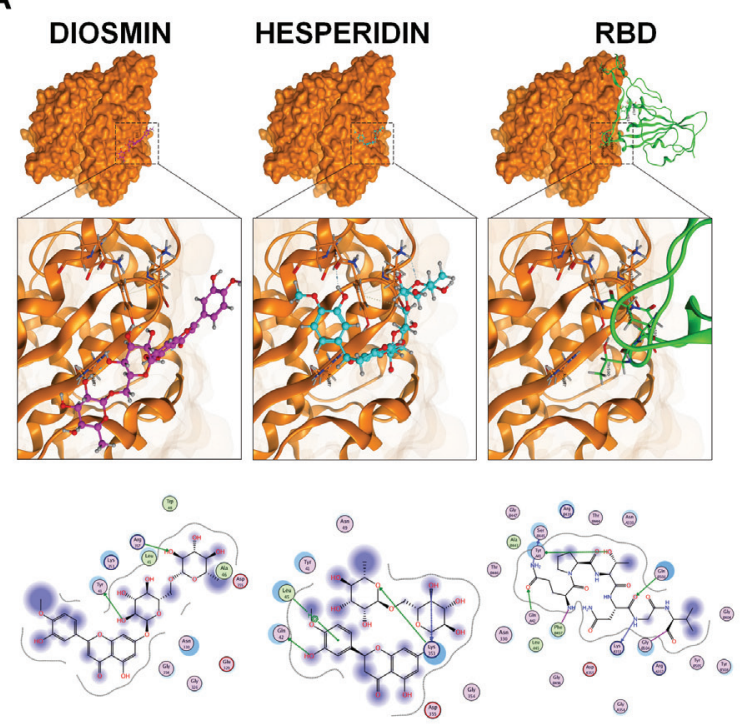

B

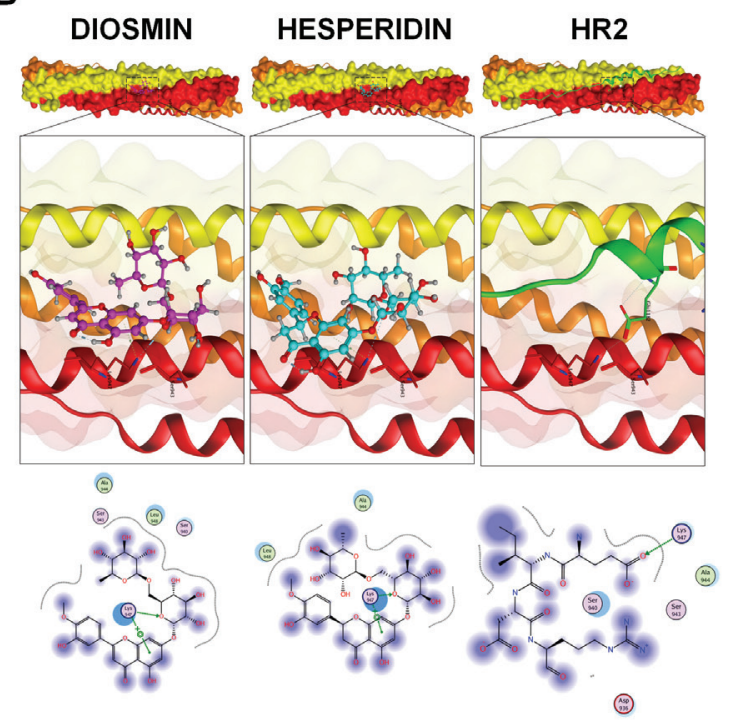

C

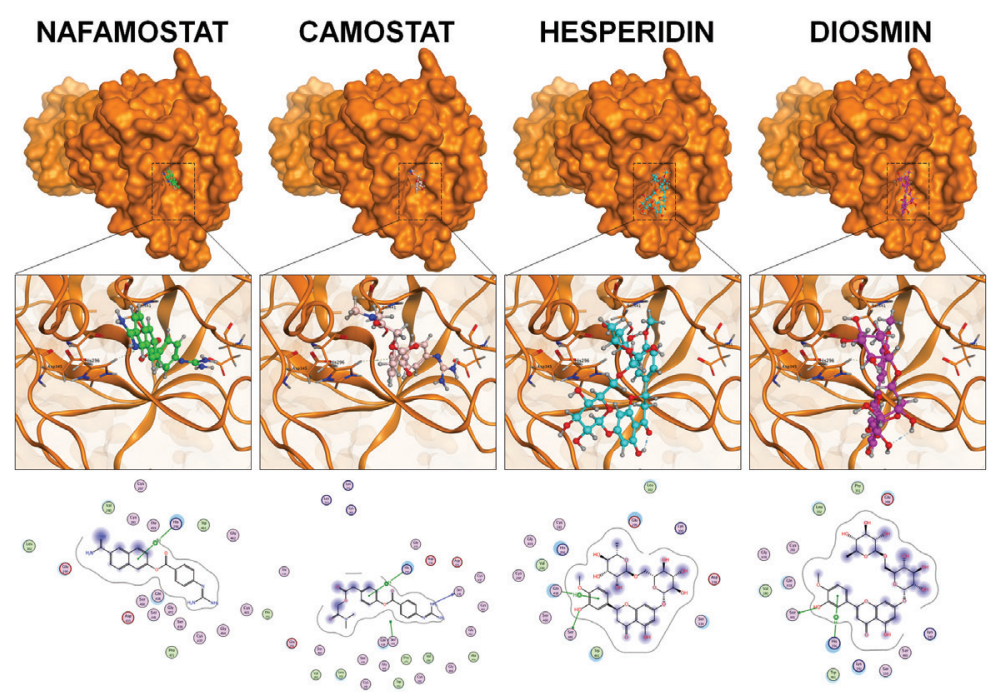

Figure 4. (A). Binding interaction of RBD of SARS-CoV-2, hesperidin, and diosmin on protease domain of ACE2. ACE2 was shown in orange-colored surface while the RBD was in green-color ribbon. The binding site of RBD of SARS-CoV-2 on ACE2 was highlighted in a dashed line. All of the compound was represented in a ball and stick-colored atom. (B). Binding interaction of HR2, hesperidin, and diosmin on S2 subunit of spike glycoprotein. Trimeric S2 subunit was shown in colored surface while the HR2 was in greencolor ribbon. The binding site of HR2 on the S2 subunit was highlighted in a dashed line. All of the compound was represented in a ball and stick-colored atom. (C). Binding interaction of nafamostat, camostat, hesperidin, and diosmin on protease catalytic site of TMPRSS2. Structure of TMPRSS2 was shown in orange-colored surface while the catalytic site was highlighted in a dashed line. All of the compound was represented in a ball and stick-colored atom. 
Utomo, 2020

Indones. J. Cancer Chemoprevent., 11(3), 154-167

Table 2. The chemopreventive properties of diosmin and hesperidin.

\begin{tabular}{|c|c|c|c|c|c|}
\hline \multicolumn{3}{|c|}{ Diosmin } & \multicolumn{3}{|c|}{ Hesperidin } \\
\hline $\begin{array}{c}\text { Chemopreventive } \\
\text { activity }\end{array}$ & Target Mechanism & R eference & $\begin{array}{c}\text { Chemopreventive } \\
\text { activity }\end{array}$ & Target Mechanism & Reference \\
\hline $\begin{array}{l}\text { Antimicrobial } \\
\text { Infection (TB MDR) }\end{array}$ & $\begin{array}{l}\text { Binds to L,D- } \\
\text { transpeptidase (Ldt) } \\
\text { M. tuberculosis (in } \\
\text { silico) }\end{array}$ & $\begin{array}{l}\text { Pushkaran, et. al., } \\
2019\end{array}$ & Anticancer & $\begin{array}{l}\text { Inhibits the } \\
\text { proliferation of MCF } \\
7 \text { GFP Tubulin cells } \\
\text { and LNCaP cells. }\end{array}$ & $\begin{array}{l}\text { Lee, et.al., } \\
2010\end{array}$ \\
\hline Immunomodulator & $\downarrow$ IL-I $\beta$, IL-8, TNF- $\alpha$ & $\begin{array}{l}\text { Zaragoza, et. al., } \\
2020\end{array}$ & & $\begin{array}{l}\text { Inhibits T47D cell } \\
\text { proliferation }\end{array}$ & $\begin{array}{l}\text { Da'l, et. al., } \\
2019\end{array}$ \\
\hline \multirow[t]{2}{*}{ Anticancer } & $\begin{array}{l}\text { A ttenuated the } \\
\text { damage to lung } \\
\text { epithelium, } \downarrow \text { NF-kB, } \\
\text { COX2, IL-6, Bax, } \\
\text { cleaved caspase 3, and } \\
\text { cleaved PARP protein }\end{array}$ & Islam, et. al., 2020 & & $\begin{array}{l}\text { Inhibits of Akt and } \\
\text { NF-kB signaling and } \\
\text { MMP-9, MMP-2 } \\
\text { activation. }\end{array}$ & $\begin{array}{l}\text { Kongtawelert, } \\
\text { et. al., } 2020\end{array}$ \\
\hline & $\begin{array}{l}\downarrow \text { TNF- } \alpha, \text { COX-II } \\
\text { and MPO and } \\
\text { caspase-3 }\end{array}$ & $\begin{array}{l}\text { Shalkami, et. al., } \\
2017\end{array}$ & Cardioprotective & $\begin{array}{l}\downarrow \text { creatine kinase- } \\
\text { muscle/brain, cardiac } \\
\text { troponin I and } \uparrow \\
\text { cardio } \\
\text { histopathological } \\
\text { scores }\end{array}$ & $\begin{array}{l}\text { Saad, et. al., } \\
2020\end{array}$ \\
\hline $\begin{array}{l}\text { Hepatoprotective } \\
\text { Cardioprotective } \\
\text { Nephroprotective }\end{array}$ & $\begin{array}{l}\downarrow I L-I \beta, I L-6, T N F-\alpha \\
\text { and } \uparrow \text { antioxidant } \\
\text { enzymes }\end{array}$ & $\begin{array}{l}\text { Abdael-Daim, et. } \\
\text { al., } 2017\end{array}$ & Hepatoprotective & $\begin{array}{l}\uparrow \mathrm{Nrf2} \text { and HO-I, } \\
\text { antioxidants level. } \downarrow \\
\text { HMGBI protein, IkB } \alpha \text {, } \\
\text { MMP-9 and C-reactive } \\
\text { protein. }\end{array}$ & $\begin{array}{l}\text { Tabeshpour, } \\
\text { et. al., } 2019\end{array}$ \\
\hline $\begin{array}{l}\text { Antidiabetic and } \\
\text { hiperlipidemic }\end{array}$ & $\begin{array}{l}\text { Activates I-2R to } \\
\text { enhance the secretion } \\
\text { of } \beta \text {-endorphin and } \\
\text { influences metabolic } \\
\text { homeostasis }\end{array}$ & Hsu, et.al., 2017 & Nephroprotective & $\begin{array}{l}\downarrow \text { urea, uric acid, } \\
\text { potassium, and follicle- } \\
\text { stimulating hormone } \\
\text { levels, and NF-кB } \\
\text { immunoexpression }\end{array}$ & $\begin{array}{l}\text { Abd-Elhakim, } \\
\text { et. al., } 2020\end{array}$ \\
\hline
\end{tabular}

peridin and diosmin show additional ionic interaction at Ile418 which potentially contribute to the stronger binding properties (Figure 4).

Nevertheless, we analyzed the model interaction between diosmin and hesperidin on the complex structure of RBD-S/PD-ACE2 (6VW1) in comparison with other compounds. We found that diosmin and hesperidin showed the best interaction among the tested compounds with $\Delta \mathrm{G}$ values of -10.98 and $-10.67 \mathrm{Kcal} / \mathrm{mol}$ respectively (Table 1 ). All the compounds were docked at the same envi- ronment as the RBD-S position. Some amino acid residues that may be interrupted by diosmin and hesperidin are Leu45, Tyr41, and Lys353 (Figure 4A). These complex interactions among the amino acid residues could inhibit the recognition of RB$\mathrm{D}-\mathrm{S}$ to PD-ACE2, which is subsequently preventing virus infection.

Moreover, we also realized that hesperidin and diosmin performed better binding interaction to the HR2 binding domain of S2 (S2 sub unit: 6LXT) (Figure 4B) compared to other tested compounds. 
Besides, they are both also superior in bond strength to TMPRSS2 protease like domain among the other test compounds (Figure 4C). We found that the interaction between TMPRSS2 with diosmin and hesperidin are stronger compared to nafamostat and camostat showing the $\Delta \mathrm{G}$ of $-14.16 ;-12.71 ;-11.30$ and $-11.19 \mathrm{Kcal} / \mathrm{mol}$ respectively. The results show that diosmin and hesperidin are prospects to inhibit the entry of SARS-CoV-2 into human cells through inhibiting TMPRSS2. Then next, we examine the possibility of amino acid residues of TMPRSS2 that are responsible for binding between diosmin and hesperidin with the protein target. In this regard, hesperidin and diosmin dock in the same amino acid residues environment as nafamostat and camostat. His296, GLN438, and Ser441 are the three amino acid residues that dominantly share interaction with the docking compounds. However, diosmin and hesperidin may give more hydrogen binding than nafamostat and namostat resulting in the strengthening of binding interaction.

These findings actually highlighted the potential of selected compounds and medicinal herbs, especially diosmin and hesperidin as anti SARSCov-2 by the strong interaction against some indispensable proteins for SARS-CoV-2 infection including SARS-CoV-2 protease (PDB:6LU7), Spike glycoprotein-RBD (PDB:6LXT), TMPRSS2, and PD-ACE2 (PDB:6VW1). For more complete consideration, the potential of the compounds to overcome or to protect the comorbid diseases of COVID-19 should be considered. Several types of symptoms and diseases that can aggravate the viral infection condition have been noted, for example inflammation, damage to the kidneys, liver, cardiovascular and respiratory system or digestive tracts as well as cancer.

Diosmin elicits an anticancer effect towards lung cancer by attenuated the damage of lung epithelium, and reduce inflammation markers such as NF-kB, COX2, IL-6, Bax, cleaved caspase 3, and cleaved PARP protein (Islam, et. al, 2020) (Table 2). While hesperidin reported to suppress proliferation of breast cancer cells and prostate cancer cells (Kongtawelert, et. al., 2020; Lee, et.al., 2010) (Table 2). Both diosmin and hesperidin also reported for its activity to prevent and or suppress cardiac myocytes (Saad, et. al., 2020), hepatic cells (Tabeshpour, et. al., 2019) and renal cells damages (Abd-Elhakim, et. al., 2020; Abdael-Daim, et. al., 2017) by decreasing proinflammatory cytokines (Shalkami, et. al., 2017) which also possibly related to its antioxidant activity. Although it is possible to use diosmin and hesperidin as a therapeutic agent, previous study highlighted that the effect was way more significant when it was administered as a prophylaxis to prevent the disease initiation or progression (Abd-Elhakim, et. al., 2020). It was also mentioned that diosmin effectively prevents TBMDR infection by strongly binding to L,D-transpeptidase (Ldt) (an essential protein determining $M$. tuberculosis virulence) (Table 2).

Diosmin and hesperidin have been gaining popularity globally due to their potential pharmacology effect as cardioprotector, hepatoprotector, nephroprotector, antivirus, antimicrobial, antidiabetic, anticancer and influencing immunomodulation activities (Table 2). Either alone or in combination, they are able play a pivotal role to produce a biological and therapeutic action to modulate the activities of various targets, depending on their physicochemical and structural properties (Meiyanto and Larasati, 2020). Many of stated effects are apparently related to COVID-19 comorbid pathology (de Lucena, et. al., 2020).

The symptoms of COVID-19 are proven to be worse in patients with comorbidities. According to CDC, patients with diabetes mellitus type 2, coronary artery disease, heart failure, chronic kidney disease, chronic obstructive pulmonary disease, and immunocompromised condition are vulnerable to the SARS-CoV-2 infection (Guan, et. al., 2020). If diosmin and hesperidin are known for its protective activity towards certain organs through various mechanisms, we suspect that the effect can ease the symptoms and cytokine cas- 
cades of SARS-CoV-2 infection in patient with related comorbidities. Through these various targets we might also draw a pattern of chemopreventive activity of diosmin and hesperidin. Furthermore, it might be promoted as chemopreventive agents, an agent which is able to suppress or prevent either the initial stages or progression of a certain disease not only for COVID-19.

This finding regarding the strong ability of diosmin and hesperidin to interact with TMPRSS2 raises the other benefit of those compounds. TMPRSS extracellular domain plays an essential role in virus endocytosis towards the host cells. While the intracellular domain is essential for determining interaction with cytoskeletal components and signaling molecules for self-correcting intracellular traffic peptides. The stem region domain acts as a key mediator for protein interaction and binding site (Thunders and Delahunt, 2020; Afar, et. al., 2001). The catalytic domain might cleave cell membrane receptors and extracellular matrices. The TMPRSS2 are homologues with 2 types of isoform. The isoform II is the 492 amino acids while the alternative splicing of its m-RNA might result in isoform I (Zmora, et. al.,2015). The fusion of TMPRSS2 with ERG (erythroblast-specific-related gene), an oncogenic transcription factor, is the most common chromosomal aberration in prostate cancer and explains the overexpression of the ERG proto-oncogene seen in malignant cells (Murray, et.al., 2016). The inhibition of TMPRSS2 might lead to reduce malignancy in tumor progression. This fact may explain the anticancer activity of diosmin and hesperidin (Islam, et. al., 2020).

Diosmin and hesperidin are the major compounds of Citrus sp. and can be extracted with an abundant amount from the peel ranging about 0.2$2.3 \%$ of dried peel. Extraction with the Hydrodynamic cavitation (HCE) system could be the best choice to gain a complex mixture of hesperidin/ diosmin-pectin (Meneguzzo, et. al., 2020). The complex hesperidin/diosmin-pectin can be proceeded further to obtain the purified hesperidin/ diosmin, or complex hesperidin/diosmin-pectin dry powder. All of the process to collect the complex pectin only needs several hours including the preparation of the peel powder with a low cost, because it only uses water for extraction. Therefore, the development of hesperidin/diosmin from citrus peel is affordable in combating COVID-19 including its comorbid diseases and even may be used as chemopreventive agent for several diseases, such as cancer.

\section{CONCLUSION}

Hesperidin and diosmin perform the best binding abilities to TMPRSS, 3CL-pro, S2-RBD, and PD-ACE2 that may potential to inhibit the Sars-CoV-2 infection and development. Hesperidin and diosmin also possess chemopreventive properties against cancer, cardiovascular diseases, diabetes syndromes, viral infection, inflammatory symptoms that beneficial to combat the comorbidities of COVID-19 and reduce the fatality risk.

\section{ACKNOWLEDGEMENT}

We are thanks to COVID-19 project under BRIN and LPDP funding 2020 with a contract number of: 72/F1/PKS-KCOVID-19.D/VI/2020.

\section{REFERENCES}

Abd-Elhakim, Y.M., Ghoneim, M.H., Ebraheim, L.L. and Imam, T.S., 2020, Taurine and hesperidin rescues carbon tetrachloride-triggered testicular and kidney damage in rats via modulating oxidative stress and inflammation, Life Sciences, 254, 117782.

Abdel-Daim, M.M., Khalifa, H.A., Abushouk, A.I., Dkhil, M.A. and Al-Quraishy, S.A., 2017, Diosmin attenuates methotrexate-induced hepatic, renal, and cardiac injury: a biochemical and histopathological study in mice, Oxidative medicine and cellular longevity, 2017, 3281670 
Afar, D.E., Vivanco, I., Hubert, R.S., Kuo, J., Chen, E., Saffran, D.C., Raitano, A.B. and Jakobovits, A., 2001, Catalytic cleavage of the androgen-regulated TMPRSS2 protease results in its secretion by prostate and prostate cancer epithelia, Cancer research, 61(4), 1686-1692.

Cao, B., Wang, Y., Wen, D., Liu, W., Wang, J., Fan, G., et. al., 2020, A Trial of Lopinavir-Ritonavir in Adults Hospitalized with Severe Covid-19, N Engl J Med., 382(19), 1787-1799.

Chan, J.F., Kok, K., Zhu, Z., Chu, H., To, K.K., Yuan, S., et. al., 2020, Genomic characterization of the 2019 novel human-pathogenic coronavirus isolated from a patient with atypical pneumonia after visiting Wuhan, Emerging Microbes \& Infections, 9(1), 221-236.

Chang, Y., Tung, Y., Lee, K., Chen, T., Hsiao, Y., Chang, H., Hsieh, T., et al., 2020, Potential therapeutic agents for COVID-19 based on the analysis of protease and RNA polymerase docking. Preprints, 2020, 2020020242.

Chen, H. and Du, Q., 2020, Potential natural compounds for preventing 2019-nCoV infection, Preprints, 2020, 202001.0358.v1.

Da'i, M., Meilinasary, K. A., Suhendi, A. and Haryanti, S., 2019, Selectivity Index of Alpinia galanga Extract and 1'-Acetoxychavicol Acetate on Cancer Cell Lines, Indonesian Journal of Cancer Chemoprevention, 10(2), 95-100.

Darmawan, E. and Pramono, S., 2016, Essential Oil of Javanese Turmeric (Curcuma xanthorrhiza, Roxb) Decrease Level of LDL-Cholesterol and Body Weight in Rats, Indonesian Journal of Cancer Chemoprevention, 7(1), 6-8.

de Lucena, T., Silva Santos, A.F., de Lima, B.R., de Albuquerque Borborema, M.E. and de Azevêdo Silva, J., 2020, Mechanism of inflammatory response in associated comorbidities in COVID-19, Diabetes \& metabolic syndrome, 14(4), 597600.

Folegatti, P.M., Ewer, K.J., Aley, P.K., Angus, B., Becker, S., Belij-Rammerstorfer, S., et. al., 2020, Safety and immunogenicity of the ChA- d0x1 nCoV-19 vaccine against SARS-CoV-2: a preliminary report of a phase $1 / 2$, single-blind, randomised controlled trial, Lancet, 396(10249), 467-478.

Guan, W.J., Liang, W.H., Zhao, Y., Liang, H.R., Chen, Z.S., Li, Y.M., et al., 2020, Comorbidity and its impact on 1590 patients with Covid-19 in China: A Nationwide Analysis, European Respiratory Journal, 55(5), 2000547.

Harrison, C., 2020, Coronavirus puts drug repurposing on the fast track, Nature Biotechnology, 38, 379-381.

Hsu, C.C., Lin, M.H., Cheng, J.T. and Wu, M.C., 2017, Diosmin, a citrus nutrient, activates imidazoline receptors to alleviate blood glucose and lipids in type 1-like diabetic rats, Nutrients, 9(7), 684.

Hussain, M., Jabeen, N., Amanullah, A., Baig, A.A., Aziz, B., Shabbir, S., Raza, F. and Uddin, N., 2020, Molecular docking between human TMPRSS2 and SARS-CoV-2 spike protein: conformation and intermolecular interactions, AIMS microbiology, 6(3), 350.

Ikawati, M., Armandari, I., Khumaira, A. and Ertanto, Y., 2019, Effects of peel extract from Citrus reticulata and hesperidin, a citrus flavonoid, on macrophage cell line, Indonesian J Pharm, 30(4), 260-268.

lqbal, M.M., Abid, I., Hussain, S., Shahzad, N., Waqas, M.S. and Iqbal, M.J., 2020, The effects of regional climatic condition on the spread of COVID-19 at global scale, The Science of the total environment, 739, 140101.

Islam, J., Shree, A., Afzal, S.M., Vafa, A. and Sultana, S., 2020, Protective effect of Diosmin against benzo (a) pyrene-induced lung injury in Swiss Albino Mice, Environmental Toxicology, 35(7), 747-757.

Kongtawelert, P., Wudtiwai, B., Shwe, T.H., Pothacharoen, P. and Phitak, T., 2020, Inhibitory effect of Hesperidin on the expression of programmed death ligand (PD-L1) in breast Cancer, Molecules, 25(2), 252.

Lee, C.J., Wilson, L., Jordan, M.A., Nguyen, V., Tang, 
J. and Smiyun, G., 2010, Hesperidin suppressed proliferations of both Human breast cancer and androgen-dependent prostate cancer cells, Phytotherapy Research, 24(S1), S15-S19.

Meiyanto, E. and Larasati, Y.A., 2019, The chemopreventive activity of Indonesia medicinal plants targeting on hallmarks of cancer, Advanced Pharmaceutical Bulletin, 9(2), 219-230.

Meneguzzo, F., Ciriminna, R., Zabini, F. and Pagliaro, M., 2020, Review of Evidence Available on Hesperidin-Rich Products as Potential Tools against COVID-19 and Hydrodynamic Cavitation-Based Extraction as a Method of Increasing Their Production, Processes, 8, 549.

Meyer, J.J.M., Afoloyan, A.J., Taylor, M.B. and Erasmus, D., 1997, Antiviral activity of galangin isolated from the aerial parts of Helichrysum aureonitens, Journal of Ethnopharmacology, 56. 165-169.

Murray, A.S., Varela, F.A. and List, K., 2016, Type II transmembrane serine proteases as potential targets for cancer therapy, Biological chemistry, 397(9), 815-826.

Nogata, Y., Sakamoto, K., Shiratsuchi, H., Ishii, T., Yano, M. and Ohta, H., 2006, Flavonoid composition of fruit tissues of citrus species, Bioscience Biotechnology \& Biochemistry, 70(1), 178-192.

Parvathaneni, V. and Gupta, V., 2020, Utilizing drug repurposing against COVID-19 - Efficacy, limitations, and challenges, Life sciences, 259, 118275.

Plaze, M., Attali, D., Petit, A.C., Blatzer, M., Simon-Loriere, E., Vinckier, F., et. al., 2020, Repurposing chlorpromazine to treat COVID-19: The reCoVery study, Encephale, 46(3), 169-172.

Pushkaran, A.C., Vinod, V., Vanuopadath, M., Nair, S.S., Nair, S.V., Vasudevan, A.K.,Biswas, R. and Mohan, C.G., 2019, Combination of repurposed drug diosmin with amoxicillin-clavulanic acid causes synergistic inhibition of mycobacterial growth, Scientific reports, 9(1), 1-14.

Roser, M. and Ritchie, H., 2020, Coronavirus Disease
(COVID-19). Published online at OurWorldlnData.org. Retrieved from: 'https://ourworldindata.org/coronavirus' [Online Resource]

Saad, S., Ahmad, I., Kawish, S.M., Khan, U.A., Ahmad, F.J., Ali, A. and Jain, G.K., 2020, Improved cardioprotective effects of hesperidin solid lipid nanoparticles prepared by supercritical antisolvent technology, Colloids and Surfaces B: Biointerfaces, 187, 110628.

Sakai, K., Ami, Y., Tahara, M., Kubota, T., Anraku, M., Abe, M., Nakajima, N., et al., 2014, The host protease TMPRSS2 plays a major role in in vivo replication of emerging H7N9 and seasonal influenza viruses, Journal of virology, 88(10), 5608-5616.

Salehi, B., Fokou, P.V.T., Sharifi-Rad, M., Zucca, P., Pezzani, R., Martins, N., et al., 2019, The therapeutic potential of naringenin: a review of clinical trials, Pharmaceuticals, 12, 11.

Shalkami, A.S., Hassan, M.I.A. and Bakr, A.G., 2018, Anti-inflammatory, antioxidant and anti-apoptotic activity of diosmin in acetic acid-induced ulcerative colitis, Human and experimental toxicology, 37(1), 78-86.

Tabeshpour, J., Hosseinzadeh, H., Hashemzaei, M. and Karimi, G., 2020, A review of the hepatoprotective effects of hesperidin, a flavanon glycoside in citrus fruits, against natural and chemical toxicities, DARU Journal of Pharmaceutical Sciences, 28(1), 305-317.

Tahir, U.Q.M, Alqahtani, S.M., Alamri, M.A. and Chen, L.L., 2020, Structural basis of SARS-CoV-2 $3 \mathrm{CL}$ (pro) and anti-COVID-19 drug discovery from medicinal plants, J Pharm Anal., 10(4), 313319.

Thunders, M. and Delahunt, B., 2020, Gene of the month: TMPRSS2 (transmembrane serine protease 2), Journal of clinical pathology, 2020206987.

Utomo, R.Y., Ikawati, M. and Meiyanto, E., 2020, Revealing the Potency of Citrus and Galangal Constituents to Halt SARS-CoV-2 Infection, Preprints, 2020, 2020030214. 
Wang, J., 2020, Fast identification of possible drug treatment of coronavirus disease-19 (COVID-19) through computational drug repurposing study, ChemRxiv.

Wrapp, D., Wang, N., Corbett, K.S., Goldsmith, J.A., Hsieh, C., Abiona, O., Graham, B.S., McLellan, J.S., 2020, Cryo-EM structure of the 2019-nCoV spike in the prefusion conformation, Science, 367(6483), 1260-1263.

Zaragozá, C., Villaescusa, L., Monserrat, J., Zaragozá, F. and Álvarez-Mon, M., 2020, Potential therapeutic anti-inflammatory and immuno- modulatory effects of dihydroflavones, flavones, and flavonols, Molecules, 25(4), 1017.

Zhu, F.C., Li, Y.H., Guan, X.H., Hou, L.H., Wang, W.J., Li, J.X., et. al., 2020, Safety, tolerability, and immunogenicity of a recombinant adenovirus type-5 vectored COVID-19 vaccine: a dose-escalation, open-label, non-randomised, first-inhuman trial, Lancet, 395(10240), 1845-1854.

Zmora, P., Moldenhauer, A.S., Hofmann-Winkler, H. and Pöhlmann, S., 2015, TMPRSS2 isoform 1 activates respiratory viruses and is expressed in viral target cells, PloS one, 10(9), e0138380. 